\title{
UM NOVO LÓCUS ESPAÇOTEMPORAL: CONSIDERAÇÕES SOBRE A DINÂMICA ESPACIAL E TEMPORAL DO CIBERESPAÇO
}

\author{
A NEW SPATIO-TEMPORAL LOCUS: CONSIDERATIONS ABOUT SPATIAL \\ AND TIME DYNAMICS OF CYBERSPACE
}

UM NUEVO LOCUS ESPACIO-TEMPORAL: CONSIDERACIONES ACERCA DE LAS DINÁMICAS TEMPORALES Y ESPACIALES DEL CIBERESPACIO

Gustavo Souza Santos

Docente das FIPMoc e pesquisador

do CEAD/Unimontes

gustavo.ccpv@gmail.com

Letícia Turano Trindade

Coordenadora do curso de graduação em Comunicação Social - Publicidade e Propaganda e diretora de marketing das FIPMoc

leturano@fip-moc.edu.br

Josiane Santos Brant Rocha Docente da Unimontes e FIPMoc. Pesquisadora do CEAD/Unimontes josianenat@yahoo.com.br

\section{Resumo}

A contemporaneidade tem levado o homem a indagar sobre sua realidade: acerca da fluidez cronológica diante do real e do virtual e, quanto ao espaço, interrogando sobre a geografia da conexão e da virtualidade e suas variadas interdimensões. Esse estudo propôs analisar a dinâmica do ciberespaço como um lócus espaçotemporal, essencial para a produção de identidades, performances socioculturais e sociabilidades.

Palavras-chave: Ciberespaço. Dinâmica espacial. Dinâmica temporal.

\begin{abstract}
Contemporaneity has been taken men to question about his reality: on the chronological flow under real and virtual and about space dynamics interrogating the virtuality and connection geography basis and its dimensions. This study analyses cyberspace dynamics as a spatial e temporal locus that is essential to the production of identities, cultural performances and sociability.
\end{abstract}

Keywords: Cyberspace. Spatial dynamics. Temporal dynamics. 


\section{Resumen}

El mundo contemporáneo ha llevado al hombre a preguntar por su realidad : en el flujo cronológico en lo real y lo virtual, y para la habitación, preguntándose sobre la geografía de la conexión y la virtualidad y sus variadas interdimensions. Este estudio tuvo como objetivo analizar la dinámica del ciberespacio como un lugar espacio-temporal, esencial para la producción de identidades, representaciones socio- culturales y sociabilidad.

Palabras clave: Ciberespacio. Dinámicas espaciales. Dinámicas temporales.

\section{INTRODUÇÃO}

A primeira menção do termo ciberespaço foi feita no romance Neuromancer de William Gibson, ficção científica de 1984, onde a palavra é de sua própria alcunha, relata Lévy (2000a). A compreensão de Gibson é a de um resultado de um conjunto de redes de computadores que guarda um fluxo de informações de diversas formas (LEMOS, 2008; MONTEIRO; FIDENCIO, 2013). Na narrativa, Gibson (2003) define o ciberespaço como uma espécie de alucinação consensual e internacional de apreensão de conceitos matemáticos, ainda uma representação pontual dos dados de um enredamento computadorizado humano abstraídos e um tipo de ordem informacional e técnica. Um misto tecnológico e neurológico era evocado pelo autor, numa abordagem de um tipo futurista de inteligência coletiva conceito mais tarde desenvolvido nos estudos de Lévy (2000c) -, onde um procedimento de epifania sociotécnica era traçado (GIBSON, 2003).

Tendo a alegoria expoente de Gibson em destaque, o ciberespaço é entendido por Lévy (2000a) como um espaço comunicacional aberto onde opera uma interconexão mundial de computadores e suas memórias e ainda, um conglomerado de redes digitais hiperconectadas e sem base fronteiriça, dizendo mais dos processos de criação da informação, navegação do conhecimento e tino social do que de suportes técnicos e computadorizados (LÉVY, 2000c). De encontro com a definição levyniana está a dissertada por Velloso (2008), onde o ciberespaço é uma celebração territorial e temporal de informações hipertextuais dispostas em rede. Nunes (2009) caracteriza o ciberespaço como um espaço de operações sígnicas através de informações que entrelaçadas continuamente e dispostas a dispensar novas informações dada sua marca pluritextual. Um espaço paralelo de informação e produção intelectual, uma espécie de dimensão simbólica coletiva livre, portanto, mais do que um mero meio, define Machado (2002).

Etimologicamente, cyber designa "homem do leme", "piloto" e ainda "controle" a partir do grego, como informa Monteiro (2007) que continua relatando a definição de 
cibernética proposta pelo físico Norbert Wiener nos anos 40 como ciência do controle e da comunicação sobre seres vivos e máquinas. A alcunha do físico aliada a noção preconizada pelo romancista de "Neuromancer" norteiam o pensamento de que o efeito combinado de transações humanas e tecnológicas através de máquinas resultam em cenários compostos de inteligências artificiais e paradigmas sociotécnicos outros (LÉVY, 2000a; 2000c; MONTEIRO, 2007).

A ideia de "controle" e "homem do leme" potencializam uma definição do ciberespaço como realidade espacial resultante de uma construção mais intensa da realidade e sua exploração mais densa, homem que não se satisfaz com o domínio já exercido sobre a natureza e seu curso, mas que através de um aparato técnico e comunicacional, delineia processões longitudinais do presente e futuro, como incitam a compreensão os estudos de Monteiro (2007), Nunes (2009) e Lévy (2000c).

O ciberespaço se legitimou como um lócus proeminente de representação, significação, sociabilidade e identidade, fazendo reverberar indagações sobre sua imanência no tempo e no espaço. Nesse ínterim, esse trabalho propõe analisar a dinâmica do ciberespaço como um lócus espaçotemporal, essencial para a produção de identidades, performances socioculturais e sociabilidades.

\section{DESENVOLVIMENTO}

\subsection{A processão do ciberespaço}

Convergindo o percurso da processão, Elias (2007) enxerga o ciberespaço como uma espécie de lugar-máquina, explicando que a união de tecnologia e racionalismo torna tal fenômeno instigante. $O$ autor segue contextualizando que além da tecnologia e da racionalização permitida nas esteiras do ciberespaço, um espaço de alucinação é operacionalizado, isto é, de jogo simbólico (ELIAS, 2007). Poroso e rizomático são as qualidades do ciberespaço pontuadas por Monteiro e Fidencio (2013) na promoção de inteligência coletiva (LÉVY, 2000b). Lemos (2008) possibilita um adendo afirmando que as dimensões políticas, econômicas, sociais e culturais do século XXI têm evanescido, o que significa para o autor contextualizar que, o ciberespaço será o terreno onde tais variáveis de constituição do mundo e sua ordem serão redefinidas nas proeminências do ciberespaço.

Lévy (2000a) alega que a vocação do ciberespaço é promover sinergia e interfaces para com os dispositivos de comunicação, gravação de informação, digitalização e simulação 
e, vai além destacando que o ciberespaço se tornará o principal canal comunicacional e o suporte de memória da humanidade. Associadas as definições de Lévy (2000a; 2000b) sobre o ciberespaço como coordenado de inteligência coletiva e de Lemos (2008) acerca da capacidade de síntese e lugar de redefinições paradigmáticas do mundo e dos sujeitos, observa-se que o ciberespaço por origem e definição tem uma processão ampliada no que tocam fronteiras apenas comunicacionais ou uma tendência encorajada na modernidade ou pós-modernidade. Há um oásis de experiências imbricadas no ciberespaço a requerer território, ritmo e funcionalidade (ELIAS, 2007; LÉVY, 2000b; TRIVINHO, 2007).

O homem social e histórico empreendeu ferramentas de navegação social, construção política e processão simbólica como emblemas de exploração do mundo, da realidade premente em torno de si, dos outros e das coisas (BURGOS, 2014). Seu nomadismo, posteriormente revisitado pelo sedentarismo ou fixação territorial, cedeu lugar a um status cosmopolita, típico do animal social de Aristóteles, muito embora uma nova acepção seja necessária: uma ressignificação virtual do nomadismo (LÉVY, 1993). Se por um lado, algumas ideias preconizam um movimento de desterritorialização do real pelo reino do virtual (VADICO; VIEIRA, 2013; BAUDRILLARD, 1991), há uma movimentação acústica das procedências da noção do espaço com conceitos revisitados, defende Lévy (1993). Para uma teoria de modificações da noção espacial humana, novos feitios de ferramentas de pedra polida, metais e novos materiais são potencializadas para uma perspectiva de controle dos rumos, do destino e dos autos (BURGOS, 2014). Tal ferramental como valia de controle refere-se a noção do tempo, tido hodiernamente como fragmentado (HARVEY, 2005), hipermoderno (LIPOVETSKY, 2013) e em liquefação (BAUMAN, 2007).

Por outro lado, a globalização se caracteriza pelo intercâmbio fluido e imaterial para além fronteiras através de um vórtice combinado de produtos sociais, culturais, tecnológicos, financeiros e outros em uma leitura transacional, esclarece Mattelart (2000). Nessa frente globalizada do mundo, uma esfera informatizada surge em decorrência de uma comunicação mundializada e multifacetada, emerge o ciberespaço não como princípio transacional ou germe de redefinições, mas pelo enredamento produzido e pelo expoente de um plano cada vez mais difuso, enseja Lévy (2000c). O ciberespaço aí está inserido, destarte as molas propulsoras da técnica e seu impacto (LÉVY, 2000b) e um rearranjamento dos elos sociais e simbólicos (SANTAELLA, 2003), em noções acerca do tempo e do espaço, como descritores paradigmáticos desse objeto em estudo. 


\subsection{Temporalidade no ciberespaço}

É sabido que o usufruto amplo de computadores e sistemas de processamento e armazenamento de dados instaurou o que pode ser denominado como processo de inteligência coletiva, na fala de Lévy (2000b; 2000c; 1993). O filósofo ao evocar as tecnologias da inteligência sobre o respaldo do hipertexto e hipermídia abre reflexão sobre um aspecto intrínseco da era informatizada, capital à noção do ciberespaço e paradigmático do ponto de vista de leitura histórica da realidade: a escrita revolucionou a lida com o conhecimento dispondo-o para proveito universal e permitiu a processão de uma linearidade histórica, já a informática agenciou o armazenamento de dados e sua localização e acessibilidade remota como novo formato de processão do conhecimento, com uma noção temporal elíptica (LÉVY, 1993).

Se com os modos antigos de operação simbólica observava-se uma retenção territorial ou uma inscrição disposta a conservar os saberes, no tempo da informatização o sentido de conservação se torna inerte diante de um novo, a evolução, argumenta Lévy (1993). Em outras palavras, o que a dimensão da escrita delineava como roteiro linear do presente, com o passado de aporte e uma mira ao futuro sob o estandarte da conservação, a computação e as tecnologias seccionadas no ciberespaço operacionalizam uma condensação do presente em um sentido contínuo, em andamento (TRIVINHO, 2007). Há, nas acepções de Lévy (1993) e Trivinho (2007; 2003), um estado de implosão cronológica alentado por uma ideia de tempo real e pontual perpetrado pela cultura e pensamento em redes informáticas, tendo a cultura oral e escrita se pautado por uma linearidade narrativa dos fatos e fenômenos.

Virilio (2003) destaca que a realidade não é dada livremente, e sim adquirida e gerada com o desenvolvimento das sociedades, acrescentando ainda que a maneira de se apreender a realidade é variável de acordo a evolução do conhecimento. Trivinho (2007) aprofunda essa reflexão indiciando uma nova realidade dado o contexto tecnocultural - vide ciberespaço -, a tele-existência. Tal existência potencial tem lugar em uma série de cenários e injunções antropológicas descendentes da midiatização e com corporeidade na emancipação do ciberespaço no conjunto social e na cibercultura.

$\mathrm{Na}$ temporalidade do ciberespaço, sua mecânica de armazenamento de dados, de evolução, de acessibilidade remota, de influxo de informações e conexões ampliadas designa uma dimensão axial dos indivíduos para com o tempo: as instâncias online e offline, o tempo real, o remoto e imediato, o controle, a evolução diante de um dilúvio informacional contínuo e uma desterritorialização do espaço real em um polo virtual (TRIVINHO, 2007; LÉVY, 
2000a; 2000c; QUÉAU, 2003). Uma tensão é instaurada, já que a realidade passa a se processar em uma interdimensão virtual, desmaterializada e desmaterializante, inaugurando formas de navegação social diferenciadas e dissolvendo paradigmas da narrativa do real e da história humana para criar um volume novo, não necessariamente oposto ou nefasto, mas simplesmente novo por concatenar elementos de uma realidade em interface à virtualidade (VIRILIO, 2003; LÉVY, 1993; QUÉAU, 2003).

O tempo absoluto se desfez, não havendo mais asserções de duração ou cadência cronológica, já que o tempo não é mais inteiriço, mas fracionado em explosões e instantaneidades capitaneadas por técnicas comunicacionais, pontua Virilio (2003). A leitura cabal de Virilio (2003) faz questionar se uma arritmia temporal ou alguma espécie de tensão fora causada e que efeitos podem ser observados nesse movimento de transformações abruptas e de um silêncio suave, observadas. Lévy (1993) indaga se esse cenário anunciaria o fim da história e questiona se a perspectiva histórica desertou-se da cultura informáticomidiática. Todavia, a sombra do ciberespaço que enreda a cultura, o fazer histórico e a sociedade não tem a princípio a orientação de soçobrar a ordem das coisas, sujeitos, identidades e coletividades (LÉVY, 2000a; 2000b; 2000c; 1993). O que os teóricos discutem é, antes de tudo, uma inserção da realidade humana nessa atmosfera capitaneada pela informação e comunicação (VIRILIO, 2003; LÉVY, 2003; QUÉAU, 2003).

As discussões sobre a temporalidade no ciberespaço têm o quinhão de entender sua processão na realidade humana e reverberações sociais, culturais e de outras naturezas, assim Virilio (2003) e Lévy (1993) observam que é a alta velocidade o esteio ontológico do tempo (como também o espaço) no ciberespaço, e nesse ínterim é possível apontar três leituras principais das acepções do tempo: existência, navegabilidade e memória.

A primeira leitura remete a existência modulada entre online e offline. Os sujeitos caminham e processam os atos de ser e estar no ciberespaço através de instâncias conectadas e introjetadas e um perímetro não simplesmente histórico, mas sociotécnico e técnico cultural (LÉVY, 2000a; 2000c; 1993). Os atos sociais, a performance humana e o desempenho social está entrelaçado a conexões, acessos e reflexos (QUÉAU, 2003). Se a hiperconectividade, amparada pelo enredamento comunicacional, promove encontros e instantaneidades ou imediatismos (VIRILIO, 2003) enquanto conexão ativa ou online, fora desse contexto ou em offline, não há um desligamento da fruição, esta é continuada (LÉVY, 2000a). Cumpre ressaltar que a existência no ciberespaço é modular, ou seja, se fragmenta nas instâncias online e offline, o que significa intuir, que o sujeito inteiro se fragmenta ao trafegar por essas duas esferas e processar seu ser, estar e agir, observa-se nos estudos de Trivinho (2007). 
A existência supõe uma performance no tempo e no espaço como construção da realidade de si e das coisas (TRIVINHO, 2007). Uma leitura de Lévy (1993) faz estabelecer uma leitura de contraste entre a operação simbólica e linguística da escrita e oralidade como constructo do real e o cenário tecnocultural de base informacional onde o ciberespaço é emblemático. Para ele, o modelo digital não é lido e interpretado como um texto comum, mas interpretado de modo interativo, opondo o modelo analógico à plasticidade e maleabilidade do modelo informático (LÉVY, 1993). A questão do tempo e da navegabilidade no ciberespaço fica aí expressa, quando não é possível pensar em uma narrativa linear, uma vez que a velocidade das informações e a pluraridade desencadeiam um processo multivetorial de linguagem, narrativa e exploração do conhecimento (LÉVY, 2000c). A etimologia do termo "ciber" prevê o sentido de "homem do leme" ou "piloto" (MONTEIRO, 2007), se aplica a esse cenário onde os sujeitos não mais navegam linearmente conservando dados e memória, mas trafegam em afluxo veloz e evolutivo.

Face à contravenção de narrativas lineares e de uma existência online e offline, a terceira leitura da temporalidade se pauta em razão da memória, catalisada nas definições do ciberespaço (LÉVY, 2000a; ELIAS, 2007; MONTEIRO; FIDENCIO, 2013; LEMOS, 2008). Lévy (1993) questiona se o termo memória ainda é pertinente no trato do ciberespaço considerando sua imanência estar associada fortemente a dispositivos e funções fora do corpo dos indivíduos. Em outro estudo, Lévy (2000b) explica que a constituição dessa cibermemória é assistida por dois fenômenos do ciberespaço: a multiplicação acentuada de mensagens em grande potencial e o surgimento de um fluxo intenso para tais mensagens. E é nesse esteio que Lévy (2000a; 2000b; 2000c) pontua que o ciberespaço, com sua operação de inteligência e memória coletiva, ganha espaço e repercussão como um lugar essencial de comunicação e pensamento.

Uma questão reminiscente é pensar a historicidade se a conservação do conhecimento e a processão dos atos humanos antes registrados em um princípio de acumulação e conservação através da escrita e oralidade (LÉVY, 1993) dão lugar a um ato de ebulição, atualização contínua, velocidade e evolução do conhecimento posto em acesso (ELIAS, 2007). Com uma fragmentação dos sujeitos na promoção de uma tele-existência e uma telerealidade (TRIVINHO, 2007), uma navegabilidade calcada de elementos de hipermídia e não linearidade (NUNES, 2009) e a constituição de um estado de memória potencial (LÉVY, 2000c; 1993), o ciberespaço evoca uma nova realidade de temporalidade. Todavia, o ciberespaço doravante sua particularidade temporal, efetiva-se como um lugar essencial 
aberto à energias diversas e envolto de sinergias síncronas, entre cabos, conexões, equações, funções, sociabilidade, pessoas e dados (LÉVY, 2003; 2000a; TRIVINHO, 2007).

\subsection{A geografia do ciberespaço}

O ciberespaço, diferentemente da mídia clássica, permite uma exploração comunicacional inédita, capaz de fazer subsistir uma territorialidade cadente e vivaz, seja pelas conexões, pela substância virtual da realidade, pelo hipertexto como câmbio linguístico e sígnico e toda sorte de acepções plásticas e mutantes, dada o pulso veloz a que são produzidas, socializadas e transformadas as informações nesse meio, sustentam Lévy (2000b) e Trivinho (2007).

Rodrigues (2006) argumenta que a midiatização sob a qual a sociedade está imersa hoje, desde as construções operadas pela mídia clássica e as instauradas pelo ciberespaço e sua processão, modificou substancialmente as relações sociais e a visão de mundo dos sujeitos. E a epifania da comunicação observada na contemporaneidade, como sinal de modernidade, permeou diversas instâncias da vida humana em efeito globalizado ascendente: caem fronteiras, formam-se laços, abrem-se fluxos (MATTELART, 2000). Diante desse quadro de midiatização franca e globalização da comunicação, a quotidianidade humana é influenciada e deita raízes em novos solos, pende um novo ordenamento social e espacial (LÉVY, 2003; AZEVEDO; MONTEIRO, 2010).

Lévy (2003) destaca que desde eras primitivas a comunicação operou transformações modificando o devir humano. Do homo erectus ao homo sapiens, todos os ancestrais humanos dividiam uma territorialidade comum, situada na África oriental, todavia após o desenvolvimento linguístico e consequente eixo simbólico e de conhecimento da realidade, uma diáspora é estabelecido, promovendo um novo circuito territorial de processão humana, desenvolvem Burgos (2014) e Lévy (2003). O desenvolvimento de habilidades cognitivas complexas e operações simbólicas no usufruto da linguagem e o desencadeamento da organização social foi capaz de fazer o homem inteligir e explorar o espaço à sua volta de modo cadente (BURGOS, 2014; AZEVEDO; MONTEIRO, 2010).

A processão do ciberespaço faz discutir definições sobre a realidade e sua apropriação face ao ideário da realidade virtual e da ubiquidade informacional (FONSECA, 2006; LEMOS, 2008). E fazendo uma tessitura da revolução técnica, informacional e comunicacional presente nas discussões do ciberespaço, observa-se a fundamentação de um espaço novo, figurado na técnica e forjado em uma tecnocultura (LÉVY, 2000c). Inicialmente 
porque o advento das tecnologias da informação e comunicação supõe uma modalidade ubíqua de território pela conexão, armazenamento de dados e frequência online e offline (LÉVY, 1993; 2000d); a seguir porque essa noção espacial não é restritiva ou produto único da tecnologia de hardware ou software, mas multiplica-se em modalidades de navegação social e fruição humana virtual (LÉVY, 2000a).

Santos (2004) afirma que as técnicas, aqui no contexto do ciberespaço, constituem meios instrumentais e sociais com os quais o homem organiza e promove suas vivências, criando e produzindo espaço. Depurando essa asserção a partir dos estudos de Azevedo e Monteiro (2010), que as técnicas que se apresentam como redutos da dinâmica do ciberespaço e como entendimento primário de sua leitura, são mediadoras dos atos humanos e das relações sociais em função de exploração, organização e navegabilidade. O surgimento vertiginoso de técnicas que se acoplam à quotidianidade com finalidade construtiva e organizadora da atividade humana pode ser visto como respostas ou padrões de necessidades materiais humanas (SANTOS, 2004), como outrora o ferramental humano primitivo permitia (BURGOS, 2014; LÉVY, 2003), de conhecimento do mundo (AZEVEDO; MONTEIRO, 2010).

Para o preparo de um roteiro de entendimento da dimensão espacial do ciberespaço, é importante mergulhar em dois momentos da pré-história: o primeiro diz da explosão populacional do homem na diáspora primitiva com um nomadismo que leva a operações de povoamento, exploração e apropriação territorial; o segundo momento diz da revolução neolítica, marcada pelo sedentarismo e a efetivação organizada e sistematizada da ação humana no território (LÉVY, 2003; BURGOS, 2014). Esse espectro da atividade humana primitiva, como se teoriza, faz desprender uma reflexão pontual do homem na elaboração de uma complexão do pensamento espacial no ciberespaço (AZEVEDO; MONTEIRO, 2010; LEMOS, 2008). O ciberespaço evoca essas duas moções humanas de nomadismo e sedentarismo (LÉVY, 1993), observáveis pela conectividade ampla, acessibilidade remota, contingente armazenado, ubiquidade, imaterialidade, convergência e globalização tida nos fluxos de diversas naturezas (LÉVY, 2000a; 2003).

A geografia do ciberespaço é resultante, de acordo aos estudos de Lévy (2003), Lemos (2008) e Azevedo e Monteiro (2010), de um fenômeno que soma funcionalidade técnica, organização e sistematização diante de contextos modernos e a continuidade da exploração humana teorizada na aventura do hominídeo até o homem contemporâneo. Nessa premissa de resposta à modernidade (e/ou pós-modernidade), Harvey (2005) disserta que o invólucro tecnológico da humanidade hoje aponta para tendências já enraizadas e inclinadas de 
ressignificação do espaço, alteração da concepção material e intensidade tempo-espacial. A tele-existência (TRIVINHO, 2007; BAUDRILLARD, 2011), a confabulação sobre o real e o virtual (LÉVY, 1996; MONTEIRO, 2004) e do visível/invisível (MERLEAU-PONTY, 2012) evocam uma modalidade diferenciada de posse espacial, territorialidade e dinâmica geopolítica.

A imanência do ciberespaço evoca a questão de que se há uma realidade geofísica ou de uma zona paralela ao ciberespaço, ou se sua processão indicaria um parâmetro geodésico elaborado e misto (AZEVEDO; MONTEIRO, 2010). Destarte os conceitos terminológicos de imaterialidade, ubiquidade, virtualidade, artificialidade e paralelismo, o ciberespaço poderia se caracterizar como um meio de comunicação combinado, sem uma processão espacial (LEMOS, 2008), implicando até uma nomenclatura diferente (AZEVEDO; MONTEIRO, 2010). Contudo, Machado (2002) observa que a condição do ciberespaço é de um espaço em detrimento de um meio, já que a expressão simbólica está incrustada em suas operações, não há limites para a interação de elementos linguísticos e outras atividades que não desligam sua processão ou a restringem a outro espaço, o ciberespaço é autônomo nesse sentido, configurando uma leitura para além da midiológica básica.

Lévy (2000a), em seu discurso sobre a procedência do ciberespaço, diz que sua insurgência tem base na interconexão mundial de computadores, supondo não apenas a materialidade técnica e ferramental, mas a imaterialidade das informações e dados que flutuam em seu vórtice e toda a sorte de esquemas humanos incidentes em sua processão. $\mathrm{O}$ debate de proposto por Lévy desencadeia uma reflexão ampla da geografia do ciberespaço: sua noção espacial deriva de uma ligação entre os mundos material e imaterial (LÉVY, 2000a). Entendendo o ciberespaço como uma economia de fluxos (materiais e imateriais), Santos (2004) pontua uma interdependência entre a geografia dos fluxos para com a geografia dos fixos. Isso significa dizer que o ciberespaço necessita de uma infra-estrutura disponível e exitosa para se processar, não que condicionada, mas participante, condicionante (MACHADO, 2002).

Em torno do argumento da infra-estrutura para operacionalização do ciberespaço, outro fator chama atenção: a condição democrática desse espaço, considerando que um aparato técnico precisa estar ao dispor dos indivíduos para seu pleno gozo (AZEVEDO; MONTEIRO, 2010). Todavia, Lévy (2000a) afirma o ciberespaço é um ambiente comunitário e interativo e promotor da inteligência coletiva, da qual Machado (2002) posiciona ser o fator mais revolucionário, já que permite a produção de conhecimento e a filiação a diversas redes. $\mathrm{O}$ acesso à internet e a disposição de equipamentos básicos seriam fatores condicionantes ao 
pleno exercício do ciberespaço, causando certa exclusão para o público que não dispõe do ferramental necessário, pontuam Azevedo e Monteiro (2010). Todavia, Lévy (2000a) não aponta o ciberespaço como democrático, mas observa que as tecnologias e sua repercussão crescem em ritmo acelerado e, Machado (2002) pondera que a identidade interativa e livre do ciberespaço não o desqualificam como espaço pleno, diante do debate da inclusão/exclusão digital, não restringindo a legitimação espacial dessa nova realidade midiática e social.

Sobre a legitimação espacial do ciberespaço e para uma abordagem geográfica e de alteração da concepção de espaço, Lévy (2003) destaca que a revolução em matéria de comunicação assistida nas últimas seis décadas dá conta de um processo de aproximação da humanidade, vide os autos da globalização (MATTELART, 2000), em uma comunidade integrada promovida pelas múltiplas conexões e a configuração de um espaço que permite trocas e influxos, ou uma aldeia global, sob a acepção de McLuhan (2002). Outra importante consideração diz da criação de uma elasticidade espacial, onde os dispositivos, tecnologias e hábitos desenvolvidos norteiam a sensibilidade de vastidão e promovem o encurtamento do mundo, permitindo de fato o status de comunidade uma - tal qual a evidência da existência humana primitiva -; a diáspora ainda é observável, contudo o câmbio cultural é intenso (LÉVY, 2003). Espaço elástico, ubíquo e material, integrador, encurtador, sócio-técnico, tecnocultural, características que fazem o ciberespaço compor o terreno sobre o qual a humanidade repousa seu funcionamento (LÉVY, 2000a).

\subsection{Lócus: identidades, sujeitos e coletividades}

Bezerra e Araújo (2011) afirmam que o ciberespaço como lócus expõe os sujeitos ao mesmo tempo numa relação com um "novo" e com o "outro": um "novo" capitalizado por essa nova territorialidade luminescente e caracterizada por uma velocidade frenética seja de conteúdo, recursos ou funcionalidades dispostas a facilitar o cotidiano e tornar vigorosa a rede; o "outro" remete a alteridade e a coletividade presente e participante dessa nova territorialidade, um outro a se contatar e interagir, um outro com culturas e repertórios distintos, numa teia social fascinante. O sentido da rede que se acopla ao pensamento, à comunicação prática e às relações, é uma espécie de nova ágora - digital e eletrônica - que permite algumas vantagens, como a comunicação livre e irrestrita com o mundo através de uma única interface e em um único lugar (VELLOSO, 2008).

A proeminência do ciberespaço como lócus é discutida por Guattari (2011) na problematização da subjetividade na era da assistência computadorizada, ou em contexto, nas 
vivências da era digital. O autor especula se a relação de "máquino-dependência" própria do ciberespaço não afetaria a essência dos sujeitos e a produção de subjetividade (GUATTARI, 2011). Em consonância a Guattari (2011), pode-se observar que a fecundidade sociológica do ciberespaço não emula elementos próprios da convivialidade na quotidianidade, as noções de alteridade, relacionamentos interpessoais e vínculos (COLETA; COLETA; GUIMARÃES, 2008). E nessa perspectiva, Delazari e Brandalize (2012) completam inferindo que as representações espaciais do ciberespaço convergem para um traçado sociocultural amplo em rede, dispensando práticas e promovendo autenticidade em contatos, conexões e trocas.

Sobre a legitimação do ciberespaço como lócus, Lévy (2000a) disserta um congraçamento social foi instaurado - e o que comumente é entendido por causa/efeito técnico é reconstruído como tessitura social - despertando para a emergência da cibercultura com palavras de ordem como interconexão, comunidades virtuais e inteligência coletiva. Há uma complexidade sociológica que precisa ser visitada no contexto do ciberespaço como ágora e sua condição espaço-tempo, onde Trivinho (2007) discute ser multimidiática a condição humana hoje - legitimada na tele-existência - e Guattari (2011) pontua caminhos de redefinição existencial. Sobre essa última acepção, Guattari (2011) continua afirmando que a sociabilidade eminente no ciberespaço e na cibercultura constituem a razão de viver de indivíduos e coletividades contemporâneos frente a um estado de entropia fruto da liquefação de cenários (BAUMAN, 2001; 2007; LIPOVETSKY, 2013).

\section{CONSIDERAÇÕES FINAIS}

O ciberespaço se revela como um esteio de sociabilidade, de incursões temporais e espaciais com impactos sobre a existência e a produção de subjetividade, além de uma densidade de efeitos e constituições nem frias, nem automáticas, nem dissimuladas, mas fruto de uma movimentação nas estruturas da condição humana em um advento sociotécnico. É vívida a denotação do ciberespaço como lócus no tempo - em sua fragmentação e subversão imediatista e em tempo real - e no espaço - na desterritorialização e virtualização -, pólo de energias humanas, técnicas e comunicacionais.

\section{REFERÊNCIAS}

AZEVEDO, H. L.; MONTEIRO, H. P. F. O ciberespaço em uma dimensão geográfica. Vértices, v. 12, n. 3, p. 139-147, set./dez. 2010. 
BAUDRILLARD, J. Simulacros e Simulação. Lisboa, Portugal: Relógio D’Água, 1991.

. Tela Total. Mito-ironias do virtual e da imagem. 11 ed. Porto Alegre:

Sulina, 2011.

BAUMAN, Z. Tempos líquidos. Rio de Janeiro: Jorge Zahar, 2007.

BEZERRA, M. A. A.; ARAÚJO, E. A. Reflexões epistemológicas do Orkut: ética da informação, sociabilidade, liberdade e identidade. Perspectivas em Ciência da Informação, v. 16, n. 2, abr./jun. 2011.

BURGOS, P. Conecte-se ao que importa. Um manual para a vida digital saudável. São Paulo: LeYa, 2014.

CASTRO, F. F. Fenomenologia da Comunicação em sua quotidianidade. Intercom, v. 36, n. 2, p. 21-39, jul./dez. 2013.

COLETA, A. S. M. D.; COLETA, M. F. D.; GUIMARÃES, J. L. O amor pode ser virtual? O relacionamento amoroso na internet. Psicologia em estudo, v. 3, n. 2, abr./jun., 2008.

CORREIA, J. C. Sociedade e Comunicação: estudos sobre Jornalismo e Identidades. Covilhã, Portugal: LabCom Books, 2005.

DELAZARI, L. S.; BRANDALIZE, M. C. B. Análise das redes sociais a partir do uso da informação espacial. Boletim de Ciências Geodésicas, v. 18, n. 2, p. 185-202, abr./jun. 2012.

DELEUZE, G. Diferença e Repetição. Lisboa, Portugal: Relógio D’Água, 2000.

ELIAS, H. Néon Digital. Um discurso sobre os ciberespaços. Covilhã, Portugal: LabCom Books, 2007.

FONSECA, R. Realidade Virtual x Realidade do Virtual: o controle do simulacro e a ética da criatividade. Razón y Palabra, n. 53, ano 11, out/nov. 2006.

GIBSON, W. Neuromancer. São Paulo: Aleph, 2003.

GUATTARI, F. Da produção de subjetividade. In: PARENTE, A. (Org.). Imagem-máquina: a era das tecnologias do virtual. $4^{\text {a }}$ ed. Rio de Janeiro: Editora 34, 2011. p. 177-196.

HARVEY, D. Condição Pós-moderna. 15a ed. São Paulo: Edições Loyola, 2005.

LEMOS, A. As estruturas antropológicas do ciberespaço. In: Cibercultura, tecnologia e vida social na cultura contemporânea. Porto Alegre: Sulina, 2008. 
LÉVY, P. Cibercultura. São Paulo: Editora 34, 2000a.

A emergência do cyberespace e as mutações culturais. In: PELLANDA, N. M. C.; PELLANDA, E. C. Ciberespaço: um hipertexto com Pierre Lévy. Porto Alegre: Artes e Ofícios, 2000b. p. 13-20.

Loyola, 2000c.

A inteligência coletiva: por uma antropologia do ciberespaço. 3. Ed. São Paulo: A revolução contemporânea em matéria de comunicação. In: MARTINS, F. M.; SILVA, J. M. (Orgs.). Para navegar no século XXI. $3^{\text {a }}$ ed. Porto Alegre: Sulina/Edipucrs, 2003. p. 183-204.

. Tecnologias da Inteligência. São Paulo: Editora 34, 1993.

LIPOVETSKY, G. Os tempos hipermodernos. Com Sébastien Charles. São Paulo: Edições 70, 2013.

MACHADO, J. A. S. O ciberespaço como arquitetura da liberdade. Tentativas de territorialização e controle da rede. In: ALVES, G.; MARTINEZ, V. (Org.). Dialética do Ciberespaco. Trabalho, tecnologia e política no capitalismo global. Londrina: Práxis, 2002.

MATtElart, A. A globalização da Comunicação. Tradução de Laureano Pelegrin. São Paulo: EDUSC, 2000.

MCLUHAN, M. Os meios de comunicação como extensões do homem. 12a ed. São Paulo: Cultrix, 2002.

MERLEAU-PONTY, M. O visível e o invisível. 4ª Ed. São Paulo: Editora Perspectiva, 2012.

MONTEIRO, S. D. Aspectos filosóficos do virtual e as obras simbólicas no ciberespaço. Ciência da Informação, v. 33, n. 1, jan/abr. 2004.

Ciberespaço: o termo, a definição e o conceito. Pesquisa Brasileira em Ciências da Informação e Biblioteconomia, v. 2, n. 2, 2007.

MONTEIRO, S. D.; FIDENCIO, M. V. As dobras semióticas do ciberespaço: da web visível à invisível. TransInformação, v. 25, n. 1, p. 35-46, jan./abr., 2013.

NUNES, P. Hipermídia: diversidades sígnicas e reconfigurações no ciberespaço. In: . Mídias Digitais e Interatividade. João Pessoa: Editora da UFPB, 2009, p. 219232. 
QUÉAU, P. O tempo do virtual. In: PARENTE, A. (Org.). Imagem-máquina: a era das tecnologias do virtual. $4^{\mathrm{a}}$ ed. Rio de Janeiro: Editora 34, 2011. p. 91-99.

RODRIGUES, C. Blogs e a fragmentação do espaço público. Covilhã, Portugal: LabCom Books, 2006.

ROSNAY, J. O salto do milênio. In: MARTINS, F. M.; SILVA, J. M. (Orgs.). Para navegar no século XXI. $3^{\text {a }}$ ed. Porto Alegre: Sulina/Edipucrs, 2003. p. 205-211.

SANTAELLA, Lúcia. Da cultura das mídias à cibercultura:o advento do pós-humano. Revista Famecos, Porto Alegre, v.1, n.22, dez. 2003. p. 23-32.

SANTOS, M. A natureza do espaço. Técnica e tempo, razão e emoção. 4 ed. São Paulo: EDUSP, 2004.

TRIVINHO, E. Cibercultura e existência em tempo real: contribuição para a críticadomodus operandi de reprodução cultural da civilização mediática avançada. Revista Compós, v. 9, jun. 2007.

Epistemologia em ruínas: a implosão da Teoria da Comunicação na experiência do ciberespaço. In: MARTINS, F. M.; SILVA, J. M. (Orgs.). Para navegar no século XXI. $3^{\text {a }}$ ed. Porto Alegre: Sulina/Edipucrs, 2003. p. 167-182.

VADICO, L. A.; VIEIRA, W. Dos simulacros às simulações: o ceticismo gnóstico no pensamento de Jean Baudrillard. Dispositiva, v. 2, n. 1, p. 27-44, 2013.

VELLOSO, R. V. O ciberespaço como ágora eletrônica na sociedade contemporânea. Ciência da Informação, v. 37, n. 2, mar/ago. 2008.

VIRILIO, P. O resto do tempo. In: MARTINS, F. M.; SILVA, J. M. (Orgs.). Para navegar no século XXI. $3^{\mathrm{a}}$ ed. Porto Alegre: Sulina/Edipucrs, 2003. 105-110.

Original recebido em: 28/08/2015

Aceito para publicação em: 05/12/2015

Gustavo Souza Santos

Mestrando em Geografia (Unimontes), docente das FIPMoc e pesquisador do

CEAD/Unimontes.

Letícia Turano Trindade

Coordenadora do curso de graduação em Comunicação Social - Publicidade e Propaganda e diretora de marketing das FIPMoc. Especialista em Marketing (FASA). 
Josiane Santos Brant Rocha

Doutora em Ciências do Desporto (UTAD). Docente da Unimontes e FIPMoc. Pesquisadora do CEAD/Unimontes.

(c) 